\title{
correspondence
}

\section{Is physics levelling off?}

SIR,-We thought your readers might be interested in the preliminary results of a quantitative study of the periodical literature of physics and related sciences. We have found that the growth of the literature is substantially slackening, and that the real price of a journal has doubled in the last twenty years.

For our data base, we chose a representative core of journals on the basis of our experience as physicists, and of a survey of the holdings of major libraries as well as analyses of physics literature by other workers in this field. Of the 150 journals chosen for our sample of 1977, 48 existed in 1957. The average rate of birth was approximately five new titles per annum, a new title being a completely new journal, branched title, or translated title.

Most striking of our findings is the recent levelling off in the rate of growth of our sample (see graphs $a$ and $b$ in the figure) which started in 1971-72 and, according to our estimates for 1978 , is still continuing.

How does this result compare with the general vigour of activity in physics? We have examined trends in research support, education and alternative communication systems. With the exception of Japan and West Germany, the general conclusions for major industrialised nations are that a decline began as early as 1966-67 in all three areas. In most cases the support of basic research has fallen more than of applied research.

The available statistics for the UK show that the number of postgraduate studentships awarded in physics and chemistry has remained at approximately the same level since 1966 (1,100 and 1,500 respectively). At the undergraduate level, the number of students taking physics courses declined from the peak 6,980 in 1970 to 5,792 in 1975 (or from one in nine students to one in thirteen). The statistics for the US show similar trends.

The levelling-off in the rate of growth was helped, but perhaps not caused, by the economic slump of the past five years. Does it reflect the maturity of physics and the first sign of an 'S-curve'? We hope to find out more in further studies.

We have also looked at the price of an average journal. Its cover price was \$24 in 1957 and $\$ 180$ in 1977 , or in constant dollars $(1957=100) \$ 24$ and $\$ 83$ respectively. We have used a standard volume for our studies to correct for differences in format, page size, text area and text density. It is defined as a volume of 500 standard pages $(210 \times 148 \mathrm{~mm})$ with text area of 30 picas in width and 45 lines in depth. The cost of our standard volume to the consumer was $\$ 10.70$ in 1957 and $\$ 20.40$ in 1977 (graph c) in constant dollars $(1957=100)$. However, we have not yet considered in detail changes in circulation, which could have been partly responsible for this doubling in prices. We hope to do this in another report.
It is also interesting to note that the number of new books published in physics (as listed in the British National Bibliography) declined from approximately 360 to 260 in the period 1969-77. In the same period, the average book in physics rose in price from approximately $£ 5$ to $£ 15$ at current prices but in constant pounds $(1957=100)$ it increased only marginally from $£ 3.40$ to $£ 3.90$.

\section{SEWERYN CHOMET}

King's College, Elizabeth NeJMan

University of London, UK

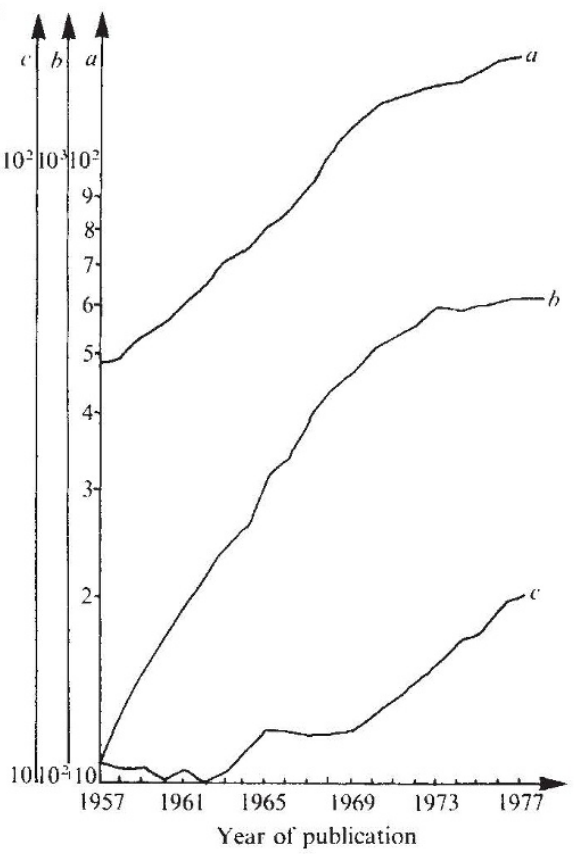

Levelling-off in physics: $a$, number of journals per year in sample; $b$, number of standard volumes per year in sample; $c$, price per standard volume in constant US dollars $(1957=100)$

\section{What happened at Hinckley Point?}

SrR,-Mr Dunster (29 March, page 393) maintains that I have seriously misunderstood the Hinckley Point incident. I used the short-hand terms 'primary' and 'secondary' for the two cooling systems, so perhaps if I outline my understanding of the incident in a little technical detail, someone can explain where the misunderstanding arises. - A sea-water pipe feeding the 'auxiliary' cooling system fractured and flooded half of the pump-house. 'Auxiliary' cooling includes the cooling for the concrete pressure vessel and its loss entails shut-down. The probability of this failure is presumably less than $1 \times 10^{-3}$ per reactor lifetime.

- Due to the failure of a sea-water valve the alternate circuit also failedthus there was a double fault. The design objective for this double failure presumably gives a combined probability less than $1 \times 10^{-6}$ per reactor lifetime, ie once in a million years or more.
- Normally the failure of the pressure vessel cooling would not lead to problems of temperature rise due to decay heat in the core, providing the gas circulators continued to operate; but was it not the case that the 'auxiliary' circuit also cooled some component of the gas circuit (the motors perhaps) and that this was a 'common-mode' design error? Mr Dunster states that the 'gas coolant' was 'unaffected'; so I may well have been misinformed.

Whatever the case, everyone insists that the gas temperatures did not rise to unacceptable levels and there was no danger of the fuel cans melting. However, it took three hours to 'jury rig' a fire hose to the 'auxiliaries'-what would have happened had it taken six hours, or twelve? No doubt when the report is published, it will contain details of temperature rise, tolerances, etc, that we may judge for ourselves.

The answer to Mr Dunster's dilemma about information being 'misquoted' is to publish more, not less. Certainly no one will then be led to think officialdom is papering over the cracks. As for 'understanding' the Hinckley Point incident, surely the real significance lies in the non-achievement of design objctives in the crucial area of safety? So far as I am aware, HSE has not made any statement of concern-so perhaps we differ as to what we see as significant.

Oxford, UK Peter TAylor

\section{Sociobiology and environmental determinism}

Sir,-_Parker (31 August, page 850) has misrepresented my review of sociobiology (Anim. Behav. 24, 707; 1976) and maligned me as an environmental determinist. Wilson misunderstands heritability and had misrepresented as success Thoday's failure to split Drosophila melanogaster into two species in laboratory experiments. I revealed what Wilson had concealed, both from his own reference where Dobzhansky (Nature 230, 289; 1971) stated that "Species formation through genetic divergence ... has not been observed ... in experiments" and from Am. Nat. (105, $83 ; 1971)$ that "Scharloo had already made unmistakably clear that "several authors in eighteen selection experiments [sic!] have tried in vain to reproduce the(ir) results'," and so on. With such unreliable treatment of insect evolution (Wilson's speciality) why heed his pronouncements about human behaviour and evolution? That was the substance of my review for which Parker pigeon-holed me with "protagonists of environmental determinism"- - a smear contradicted by both Wilson's own reference to my earlier work (Science 142, 1436; 1963) and more recent publications ( $E d$. Theory 25, 3; 1975; Proc. natn. Acad. Sci. U.S.A. 74, 5193; 1977).

University of Illinois, JERRY HrRSCH

Urbana-Champaign, Ill. 